\title{
TRANSITION ENGINEERING OF URBAN TRANSPORTATION FOR RESILIENCE TO PEAK OIL RISKS
}

\author{
Susan Krumdieck \\ Department of Mechanical Engineering \\ Private Bag 4800 \\ University of Canterbury \\ Christchurch 8041, New Zealand
}

\begin{abstract}
Oil resources are finite and production decline is a fact for this century. The question is, why there has been so little policy action? This paper proposes that dealing with the complex changes involved in the transition to oil supply contraction requires new kinds of engineering modeling and analysis. There are no miracle technologies that will mitigate the need for major policy, economic, infrastructure and land use changes. Researchers have the responsibility to develop new methods and tools necessary for policy makers and planners to manage this change in direction. Without the right tools, the policy choice is between denying the problem and hoping for miracles. With the right Transition Engineering tools, the policy choices involve changes in land use, incentives, taxes and investments that efficiently reduce vulnerability and risk, increase adaptive capacity and build resilience. For more than a decade, the research and development program at the Advanced Energy and Material Systems Lab (AEMSLab) has focused on Transition Engineering. The first Transition Engineering project assesses vulnerability and risk to essential activities from oil supply contraction in the near and long term. The risk assessment method employs a probabilistic model of future fuel availability and an impact model of travel behavior adaptation to meet the probable fuel constraint. The second project is to assess travel adaptive capacity of current travel behavior and of the current urban forms using a new kind of travel survey, and to develop adaptation models for different urban development scenarios. Another important analysis is the active mode accessibility of the current urban form. The model uses GIS data and an activity model based on the demographic profile. Future urban form development, technology and infrastructure investments and behavior change are modeled using the strategic analysis method.
\end{abstract}

\section{INTRODUCTION}

A recently published report from the UK Energy Research Centre analyses global oil depletion and provides a thorough examination of the range of expert findings (1). Any apparent disagreement or debate amongst the various experts on the timing of the peak in liquid fuel production or the subsequent decline rate is irrelevant in comparison to the implications. Within the functional lifetime of the entire transport infrastructure of the planet, the supply of fuel needed to make it function will be reducing, not growing. This simple fact seems to have garnered almost no attention from energy or transportation policy makers in any of the nations of the world. Perhaps it is not so much that governments are not paying attention, as that they have no solution options.

Transport policy makers normally have the job of deciding between alternatives. The alternatives are developed by professionals in the field, and analyzed for costs and benefits, and impacts on the economy and on the environment. Professionals rely on their education, and experience, and employ accepted analysis, modeling and design tools. The current professional training at universities and commercially available transportation surveying, modeling and planning tools, do not include consideration of oil supply depletion. New textbooks and tools become available after being developed, reviewed and accepted by the field. Research on transportation and urban planning in the context of oil depletion would normally require funding, which would depend on government recognition of the implications of the problem.

"The risks presented by global oil depletion deserve much more serious attention by the research and policy communities." (1) 
The UKERC report concludes that meaningful investment in demand reduction and substitute energy resources are the only way to avoid risks to the global economy (1). Like other previous oil supply reports, the UKERC does not investigate the consequences of supply shortages or the feasibility of mitigation approaches. However, it does stress that these should be priorities for future research. Hirsch argues that programs or changes needed to deal with shortfalls in liquid fuel supply need to be initiated several decades before the shortfall actually occurs (2). Effective engineering practice evolves from research and development, so hopefully there has been active innovation, creative thought, and investigation of peak oil risk assessment and mitigation going on in universities and national laboratories for the past decade or more.

This paper reports the peak oil research and development efforts of the past decade at the Advanced Energy and Material Systems lab (AEMSLab) in the College of Engineering at the University of Canterbury in Christchurch, New Zealand. Just as there is a lead-time with new oil discoveries to reach production, there is a necessary lead time where new research undergoes examination, peer review, improvement and application in demonstration projects. Several of the new analysis and modeling tools developed in the AEMSLab have been recently published in top engineering journals. The new Transition Engineering planning tools were deployed under contract to the Dunedin City Council in 2010 to conduct a peak oil vulnerability study (3). Case studies in Christchurch and Dunedin are used to describe the new communication approach, risk assessment tools and Transition Engineering methods.

\section{COMMUNICATING PEAK OIL RISK}

For more than a decade, the discussion of peak oil seems to have been dominated by people portrayed or perceived as alarmists. Figure 1 shows a sampling of media and internet images used in relation to the peak oil issue and risks. Most of these books, videos and blogs use data and information that is readily available, but verification and reliability of data around oil reserves, production and discoveries is problematic and can

(a)

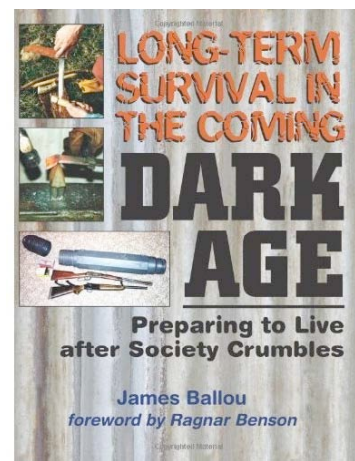

(b)

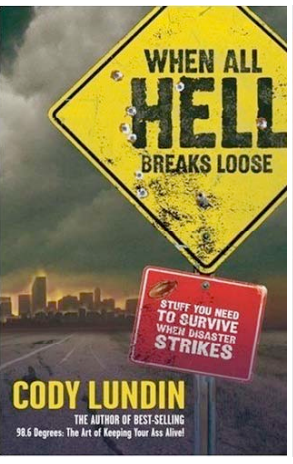

(c)

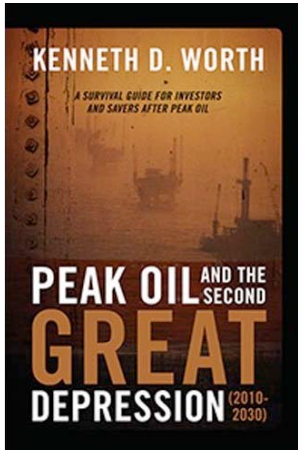

lead to the perception of uncertainty about specific details that obfuscates the certainty of the situation.

How do you move the peak oil issue forward from the arena of blogs, videos and books, and communicate it as a legitimate planning issue? (4) National governments have short or tenuous political tenure, and have a high stake in continuation of economic growth and security. After the Arab Oil Embargo and oil shocks of the 1970's the national policy response in the USA included rhetoric about reducing dependence on imported oil. Research funding over the past 30 years has been concentrated in "savior" technologies including things like hydrogen fuel cells, biofuels, electric vehicles, nano-materials, and automatic traffic controls. The current research funding programs at the National Science Foundation do not include subjects related to oil supply decline.

A key decision in the AEMSLab peak oil research was to focus on communication of risk and analysis for policy action at the local level. The vast majority of people's daily lives are carried out in the local context. The functionality of urban transport networks and goods movements depends on local land use patterns. Local councils control land use and residential developments. The capability to build new businesses that meet the needs of local people is enhanced or inhibited by local zoning and regulation agencies. The front line of peak oil risk management must be at the local level. The language of risk assessment is well known among local council workers, usually in relation to natural hazards and economic variability.

One communication problem arises from the perception of uncertainty amongst peak oil analysts as to the date of the peak in oil production and the subsequent rate of decline. A straightforward way to deal with this is a cumulative probability analysis of expert predictions (5). Figure 2 shows the results of a Raleigh curve fit to all of the primary-source analysis of peak oil dates and decline rates as given in the equation (1):

$$
P(y)=N\left(\frac{(r+y-2006) !)}{(y-2006) !(r+1) !}\right) \rho^{r}(1-\rho)^{y-2006}
$$

Fig. 1: Publications about forward planning to deal with the potential risks of peak oil abound, but the current fascination with chaotic collapse and can actually inhibit engagement and communication with policy-makers in regard to substantive planning issues: (a) J. Ballou, (b) C. Lundin, (c) K.D. Worth, (d) J.H. Kunstler, (e) M.C. Ruppert, (f) R. Heinberg. 
where $P(y)=$ Probability that peak oil will occur in year, $y$, between 2006 - 2030,

$$
\begin{array}{lrl}
\rho=\text { Fit parameter } & \text { best value } & \rho=0.46 \\
r=\text { Fit parameter } & \text { best value } & r=4.0 \\
N=\text { Time scale normalization factor for } 2005-2030 \\
& \text { best value } & N=0.4347
\end{array}
$$

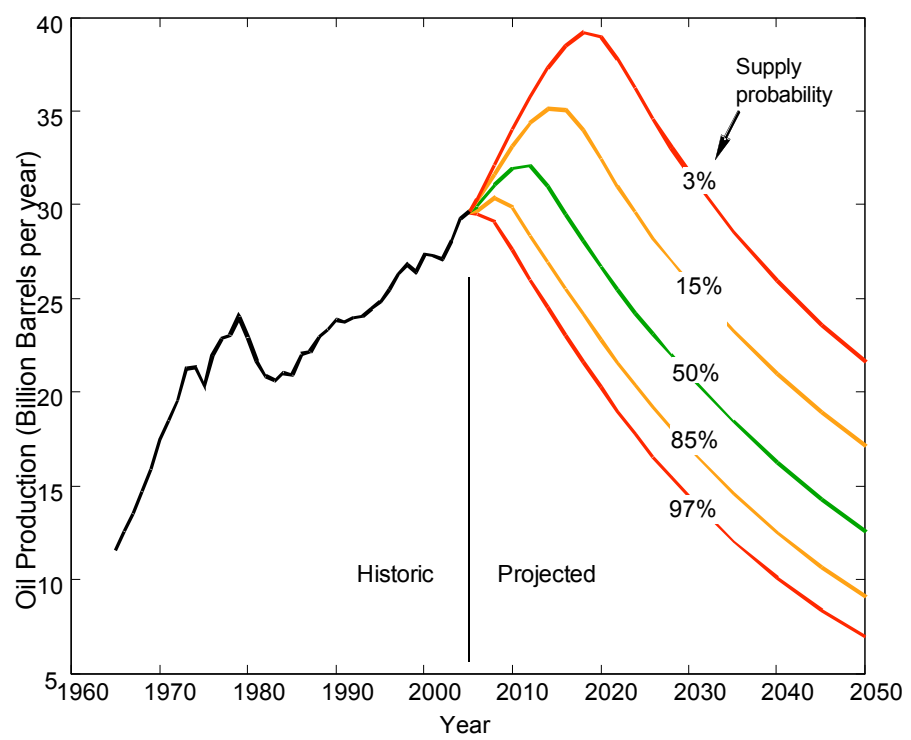

Fig. 2: The plot shows the historic world oil production data to 2005 and projected "probability space" where the probability of world oil supply level below the line is indicated as a percentage.

Each line on Figure 2 represents a level of probability that, at a particular point in the future, the world oil supply will be at least at the level indicated. This is a different type of approach from trying to actually predict a level of fuel supply or fuel demand, and which is more like the approach used to understand the risk of flood events into the future. Local planners can choose a level of probability and investigate the impacts in order to understand the potential costs of risk exposure and the benefits of mitigation options. Adaptive capacity and resilience in systems can greatly affect the level of impact that would be experienced. Council assets need to be managed to maintain their value and utility. New investment options and council long-term plan alternatives can be assessed for relative risk as a coherent approach to decision analysis.

Table 1 gives future world oil supply levels at ten-year intervals to 2050 (3). Future supply scenarios are featured in this expression of the same probabilistic modeling results used to construct Figure 1. There are political, economic, technological and environmental factors that affect the world oil supply in addition to geologic and engineering factors. This approach includes the complexity of these relationships but keeps the foundation of the scenarios simple. The level of world oil supply represented can easily be related back to the reference 2008 level.
Table 1: World oil production scenarios from the probabilistic meta analysis presented as annual average million barrels per day (mbpd) in the future year (3).

\begin{tabular}{|l|c|c|c|c|}
\hline \multirow{2}{*}{ Probability Scenario } & \multicolumn{4}{|c|}{$\begin{array}{c}\text { World Oil Production } \\
\text { (mbpd)* }\end{array}$} \\
\cline { 2 - 5 } & $\mathbf{2 0 2 0}$ & $\mathbf{2 0 3 0}$ & $\mathbf{2 0 4 0}$ & $\mathbf{2 0 5 0}$ \\
\hline Unexpected problems & 54 & 38 & 27 & 19 \\
\hline No new giant oil fields & 60 & 45 & 38 & 26 \\
\hline Most experts agree & 71 & 57 & 44 & 37 \\
\hline Discovery of Giant Fields & 85 & 68 & 58 & 48 \\
\hline
\end{tabular}

* For reference: 2008 average daily world production was $85 \mathrm{mbpd}$

Analysts who produce estimates of reserves, predictions of the peak date, and models of the decline rate use various assumptions about different factors. Table 1 lets local planners decide which type of future fits their risk tolerance based on what they think is most likely to happen. The Unexpected Problems scenario could include changes in social attitudes about environmental impacts of offshore, arctic, or tar sand production as well as political or economic disruption. The No New Giant Oil Fields scenario assumes business-as-usual political, environmental and social situations, and development of known resources with enhanced recovery, but no new technology or giant fields are discovered. The Experts Agree scenario assumes development of known and new undiscovered reserves. The Discovery of Giant Fields scenario assumes at least three discoveries the size of Saudi Arabia by 2030 or new, as yet unknown technology discovery that allows recovery of at least $75 \%$ of reserves.

\section{Experience Communicating with Local Councils}

The author had made presentations to local councils and public forums in the past about peak oil using the standard peak oil information as explained by Campbell (7). The response would typically have a bi-modal distribution between total acceptance amongst people who had already investigated peak oil, and total rejection by people who perceived the information as "doomsday" or "end of the world" in nature. The presentation of the standard information about peak oil has not been observed to stimulate action in planning or policy development. Local citizens and the individual council workers who had accepted the information would become frustrated with the lack of concern from others when they fail to accept the information.

More recently, the author has given several dozen presentations of the probability space concept in Figure 2, the scenarios in Table 1 and the risk assessment method described in the next section (8). Audiences have included professional engineering groups, city council transport and land use planners, local businesses, regional council officers, elected officials, and city council members. The person who set up the presentation was usually already convinced of the urgency of the peak oil issue and initiated the event to gain traction within the organization. Transportation planning was the typical focus of the discussions. 
Audiences would initially be skeptical of the risk presented by the peak oil issue: "The market will take care of it." "The fuel price can't go above the price of alternatives." "There can't be a shortage because the price will go up and new supplies will be brought to the market." "We have a lot of real problems to worry about, and peak oil is not one of them." "There will be new technologies brought in like electric cars and biofuels." The presentation would begin with basic facts about oil supply, along with an overview of the different expert analyses and the range of their assumptions. Then, a logical argument about how to understand a range of expert opinion would be put forward that emphasizes looking at what all the experts agree on, and being inclusive of all of the different ideas. The simple probabilistic meta-analysis method (9) would then be explained and the resulting probability space in Figure 2 discussed. The implications of reduced fuel supply in relation to current transport planning issues would then be explored in terms of infrastructure investments and value of assets. In the discussion period after the presentation, the most common immediate questions would involve alternative technologies and substitute fuels. The probability meta analysis includes the mitigating effects of alternatives, but the author would always have specific numbers available to put the mitigating effects into perspective.

The language of risk assessment, with probability and impact analysis, appears to be key to the success of the AEMSLab approach. Planners feel they have control because they choose the risk tolerance level and can use the familiar language and processes of comparative risk assessment between development options. This provides a logical and familiar way to take action on a difficult and emotive issue. The focus on investments in public assets and infrastructure, together with the cost/benefit analysis, also translates the peak oil issue into the more familiar realm of responsibilities for councilors. Comments from seminar participants in business, transportation engineering, and local councils indicate that these themes are effective at moving perception of the peak oil issue into the planning space.

\section{RISK TO ENERGY CONSTRAINED ACTIVITY AND TRANSPORT SYSTEMS}

The real issue with peak oil is that the urban form, transportation networks, vehicles and activity systems have developed to provide unconstrained mobility by using an unconstrained supply of liquid fuels. A constrained fuel supply will impact activity systems and cause changes in travel demand patterns. The Risk to Energy Constrained Activity \& Transport Systems (RECATS) method models the travel behavior changes that must occur as people adapt to constrained fuel supply. The constrained adaptation behavior model includes mode shifting, destination shifting, efficiency improvement choices, and a new model of trip elimination based on preferential preservation of trips for essential activities and to preserve wellbeing $(5,6)$.

A schematic representation of the RECATS method is shown in Figure 3 as the algorithm for the RECATS computer program. The first step is to use standard travel behavior modeling and survey data to develop the travel demand, or origin-destination (OD), matrix for the urban form under study. The study area can be a future urban development plan, a whole city, or a particular suburb. The travel demand, $T D^{m, d}$, is the number of trips per week or year using a given mode, $m$, within a given distance range, $d$. The RECATS method introduces a new concept of the travel matrix, $T^{n, d, s}$, which also includes the essentiality of each trip, $E S^{s}$. The fuel energy used in the study area to meet the travel demand is calculated from:

$$
E=\sum_{m} \sum_{d} T D^{m, d} \cdot E C^{m, d} \cdot D B^{d}
$$

where $T D^{m, d}=$ travel demand matrix for mode, $m$, and distance, $d$

$E C^{m, d}=$ energy consumption rate for each mode and distance

$$
D B^{d}=\text { vector of distance categories }
$$

At a future time, and for a given probability level, the energy supply level will be less than the current level. If a growth plan has been projected which anticipates travel demand growth, then the future probable energy available will be lower than the planned energy demand. The RECATS method changes randomly selected trips to lower energy modes or distances according to an adaptation model, recalculates the new energy used, compares it to the constrained energy level target, and either continues to adapt trips if the target is not met, or finishes the process.

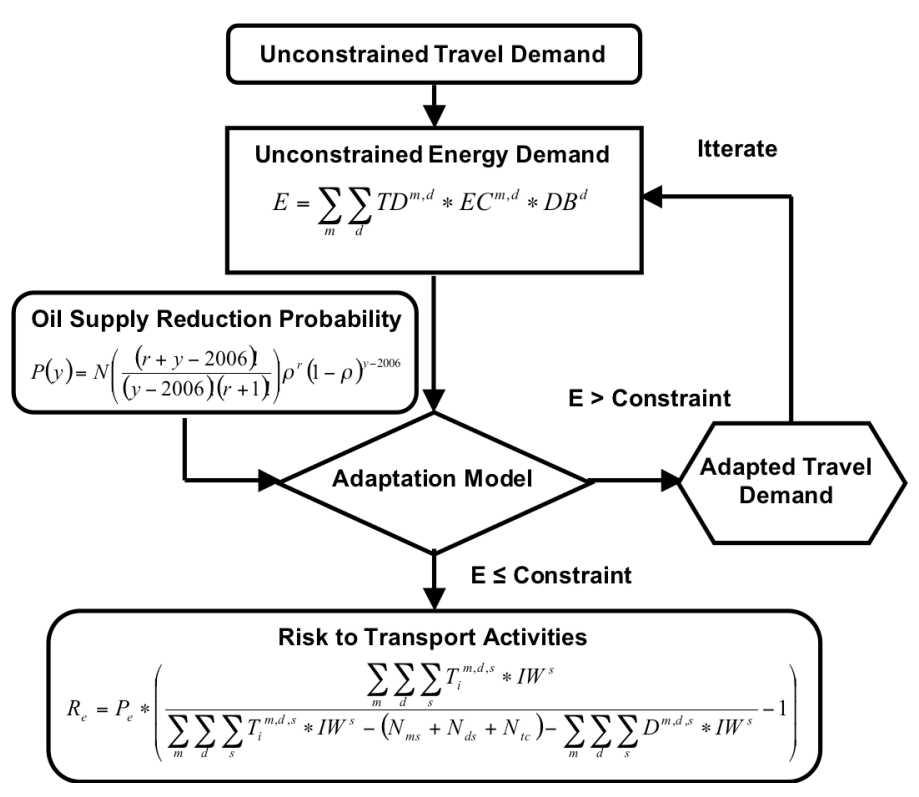

Fig. 3: The RECATS software implements the travel behavour adaptation model through an itterative proceedure that uses a Monte Carlo approach to select trips for adaptation until the total energy consumption for the study area matches the selected target level $(5,6)$. 
Trips are divided into options, necessary and essential designations. Each trip change has an associated level of impact. Changing essential trips is assumed to have the highest impact, so optional trips are changed first, then necessary, and finally essential trips. In each urban form, the percentage of car trips that can be adapted to walking, cycling, car-pooling or public transport depends on the locations of residences and destinations, the infrastructure and the public transportation services. Trips can be changed to a shorter distance category if people can move residence closer to destinations or if closer destinations are available. The adaptation model includes the percentage of each type of possible mode change and distance change.

The maximum possible adjustment of the unconstrained travel demand pattern without reducing the activity participation is referred to as the adaptive capacity. Once the adaptive capacity has been achieved, if the energy use still exceeds the constrained energy target, then trips must be lost. Optional trips in the longest distance categories are eliminated first with a higher impact than any of the mode changes, but lower than elimination of an essential trip, which is assigned the highest impact level. The process continues until the energy constraint is achieved. The risk due to energy constraint is then calculated as a non-dimensional factor according to the equation:

$$
R_{e}=P_{e}\left(\frac{\sum_{m} \sum_{d} \sum_{s} T^{m, d, s} \cdot I W^{s}}{\sum_{m} \sum_{d} \sum_{s} T^{m, d, s} \cdot I W^{s}-\left(N_{m s}+N_{d s}+N_{t c}\right)-\sum_{m} \sum_{d} \sum_{s} D^{m, d, s} \cdot I W^{s}}-1\right)
$$

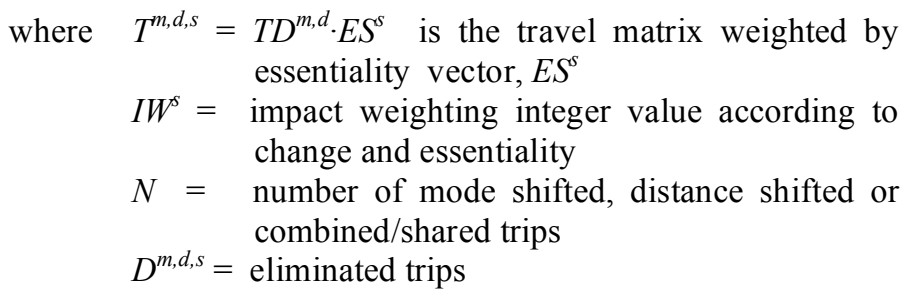

\section{Case Study: Christchurch Urban Development Plan}

Prior to the 2010-2011 earthquake events, the city of Christchurch had been experiencing population growth of about 400 people per month. The population in 2040 was predicted to reach 550,000. An urban development strategy forum (UDSF) in 2006 examined four 2041 urban forms that could result from different policy directions. City council planners evaluated four urban forms that were very distinct in the way future development is spatially distributed throughout the metropolitan area and the surrounding agricultural land. Two options are shown in Figure 4, Option A-Concentration and Option C-Dispersal. Option A was projected to have a $45 \%$ increase in fuel energy demand, while Option $\mathrm{C}$ would require 95\% more energy in 2041 than Christchurch used in 2006. At the time of the study, council acceptance of peak oil was low, so the 2041 fuel supply was projected to be only $20 \%$ less than in 2006.

Option A-Concentrated urban form has higher percentages of car trips that can be adapted to active modes and bus than the Option C-Dispersal urban form. The dispersal urban form has the classic problems of urban sprawl in that it is very difficult to use any transport mode other than private cars. The RECATS program indicated that there would be massive $(40-60 \%)$ loss

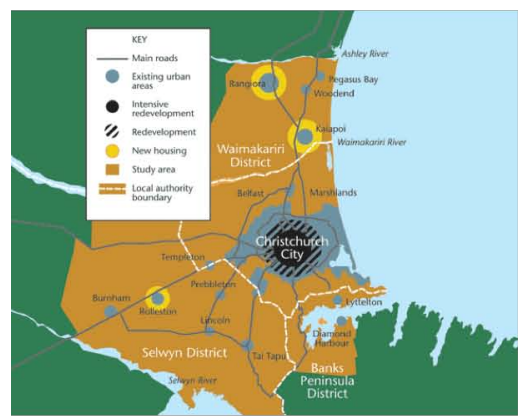

Option A - Concentration $\quad$ RECATS Risk Factor $=0.17$

Limited growth in district townships. Higher densities at some high amenity sites $40 \%$ new subdivisions around edge of towns and Christchurch $60 \%$ urban renewal in Christchurch Central City and inner suburbs Mostly dwellings without garden or yard space.

Commute takes $45 \%$ longer, $190 \%$ increase in congestion, $45 \%$ increase in transport energy use

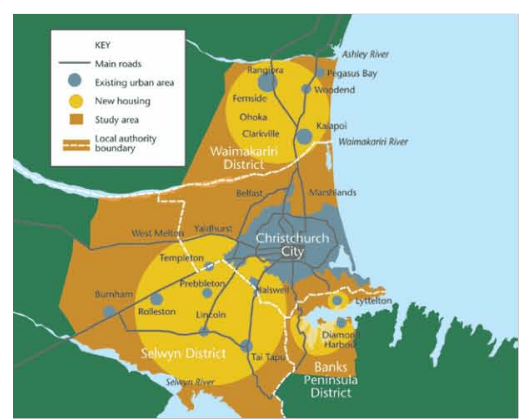

Option C - Dispersal

RECATS Risk Factor $=0.62$

Low-density, separation of homes, jobs, and services; absence of strong urban activity centres; growth occurring adjacent to but outside the city centre with a general outward migration of people 90\% new subdivisions, 10\% urban renewal in Christchurch City mostly houses, so me townhouses and apartments Commute takes $65 \%$ longer, $630 \%$ increase in congestion, $95 \%$ increase in transport energy use

Fig. 4: Two of the urban development options considered for the urban development strategy forum for Christchurch, New Zealand for target year 2041. The concentrated development option has three times lower RECATS risk factor than the urban sprawl development option 
of activity in the Option C-Dispersal urban form compared to the Option A-Concentrated city. The risk factor for the Option $\mathrm{C}$-Dispersal is more than three times higher than for the Option A-Concentrated. The Christchurch population was consulted about the development options. The Option C-Dispersal was highly unpopular with the citizenry. However, the current market trends favor developments of low density housing in the rural areas surrounding the city. The council officers who were involved in the research project in 2006 were accepting of the RECATS risk analysis results. However, they insisted that the maximum fuel reduction that councilors could contemplate would be $20 \%$, so a very low 2041 supply probability was used. It is not known what level of fuel supply constraint the council could currently contemplate.

\section{ADAPTIVE CAPACITY OF PRIVATE TRANSPORT}

The RECATS analysis has been successful in providing a starting point for action on peak oil in planning and development policy and has been used in projects for city councils. The adaptation model in the RECATS method was originally set up with general relationships based on literature review of the uptake of active modes and carpooling in different types of cities, and of public transport service levels for different types of urban forms. The focus on specific local development decisions is crucial to development of the whole Transition Engineering approach and acceptance of peak oil as a planning issue.

A research project was carried out to develop a way to measure the adaptive capacity and the public transport mode adaptive potential of the population in a particular urban area. Adaptive capacity is a measure of the maximum private car trip reduction possible without reducing participation in essential activities. Public transport mode adaptive potential is the percentage of current car trips that could be switched to public transport for the study population. These new concepts could be used to evaluate the need for change in urban form or investment in public transport. The adaptive capacity is not meant to be a predictor of actual behavior change under any specific conditions. The concept was borrowed from natural hazards engineering where adaptive capacity of civic systems is assessed for disruption from earthquakes or storms.

The Travel Adaptive Capacity Assessment (TACA) survey was developed through a $\mathrm{PhD}$ dissertation project (10). Surveys of three cities were funded by a government research grant through the New Zealand Transport Authority (NZTA). The TACA survey (11) was designed to focus on the interests and experiences of the participant. The TACA survey does not use transport engineering jargon and returns information to the participant about their weekly fuel use and their risk exposure to fuel price rise. Using the colorful, user-friendly web interface, participants enter their normal activities into a diary, which is designed to resemble a typical daytime planner. They then click on origin and destination using Google $\mathrm{Map}^{\mathrm{TM}}$ and the TACA survey records the coordinates and the routes. Figure 5 shows the trip details page for a trip on a Monday and shows the choices from each drop-down list (grey boxes) and the explanations that pop-up when the menu is clicked.

Two aspects of the survey are novel. After each trip is registered, the participant is asked to rank the importance of the activity to the household from a drop-down menu with the following pop-up explanations:

\section{Importance of the activity: \\ Low I could curtail it without suffering \\ Medium My quality of life would be reduced if I could not do this activity, but I would not surfer real harm \\ High My wellbeing would suffer and my quality of life would be reduced}

There are three drop-down lists to select $1^{\text {st }}, 2^{\text {nd }}$ and $3^{\text {rd }}$ alternatives to the mode indicated for the trip. A pop-up explanation is given when the participant clicks on the menu:

If you couldn't use your normal mode, how many other ways could you travel?

This is a novel approach in Transportation Engineering because the focus for most travel behavior studies has been on decision-making factors that would reduce congestion during the commuter rush hour (12). Researchers studied the behavior changes that occurred during the 1970's energy crisis (13), and after the temporary but disruptive fuel shortage caused by a strike in the UK in 2000 (14). The work commute trip was found to be the most resistant to change, and the most common adaptation of a shopping or social trip was cancellation or combining with other trips. Thus, having data about the perceived importance to trips in context of the available alternatives is an important new contribution. Most people don't have experience with fuel shocks, so standard stated preference survey methods are not appropriate for peak oil studies. The stated availability of alternatives to car use was developed as a way to evaluate both personal resilience and the adaptive capacity of the urban form.

\section{Case Study TACA Survey in Dunedin, New Zealand}

The Dunedin City Territorial Authority has a population of 118,683 . There are 44,349 households with a median age of 34, and median personal income of $\$ 19,400$ (15). The University of Otago is a major employer in Dunedin, with 1,174 employees. The pay scales at the university range from $\$ 26,000$ to $\$ 87,600$ for non-academic staff, and from $\$ 41,000$ to $\$ 186,000$ for academic staff (16).

The Dunedin City Council was active in promoting the survey. Newspaper articles and a radio interview were conducted several days before the survey period. The survey was conducted by random solicitation of people on the streets of Dunedin and Mosgiel and of students at the University of Otago. Rooms at the Dunedin Art Gallery and at the City Library were used to conduct the surveys. The city council randomly selected council workers and arranged appointments to take the survey. A total number of 164 surveys were conducted over a four-day period in August 2010. The dataset for Dunedin has a larger proportion of young people than the 


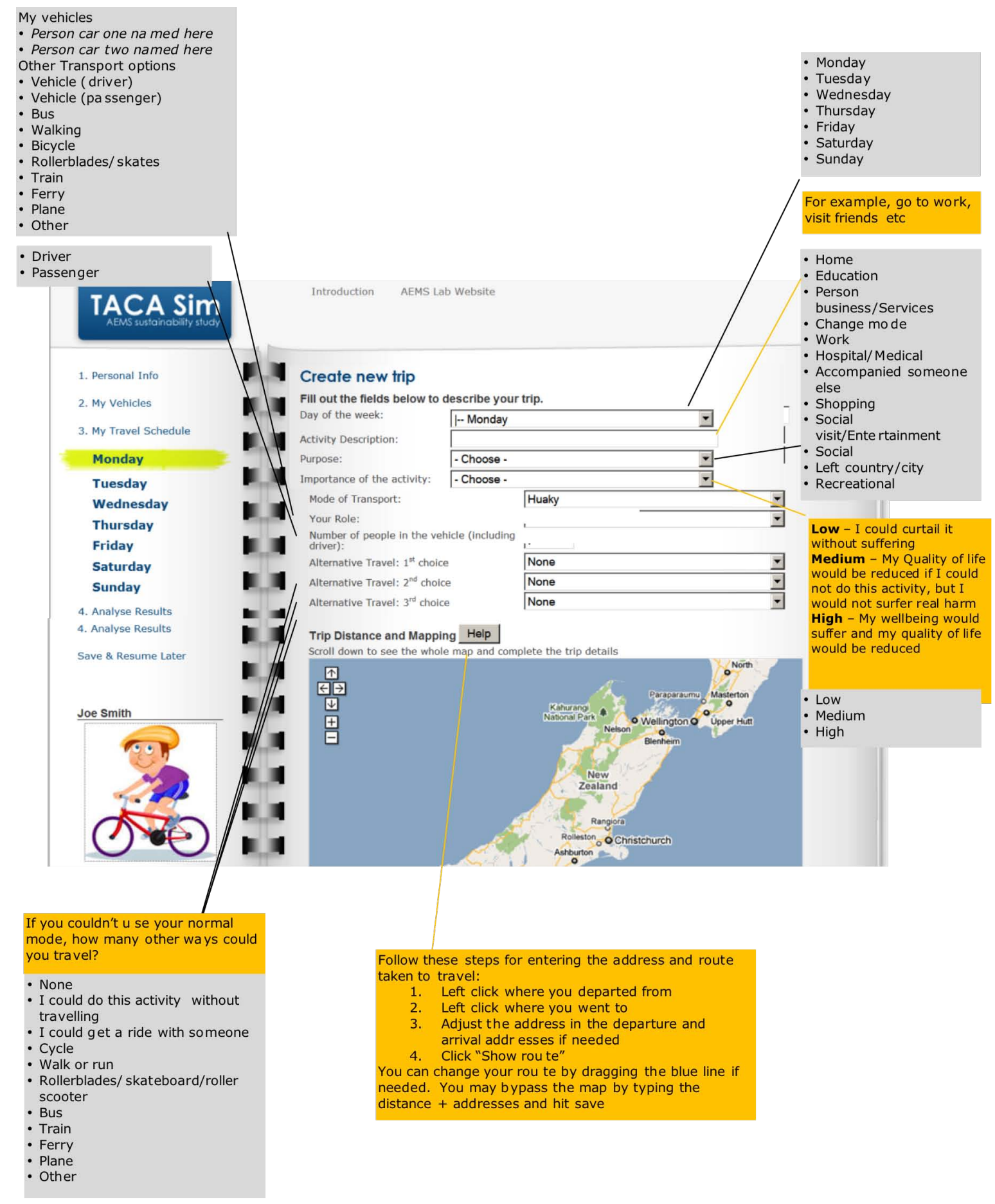

Fig. 5: TACA survey screen shot of the trip creation page with explanations in yellow boxes and contents of each drop-down list in grey boxes.

demographic profile due to targeting university and high school students.

The parameters from the TACA survey data used to calculate the personal travel adaptability, $A_{p}$ of a participant from the equation:

$$
A_{p}=1-\frac{\sum_{i=1}^{t_{p}} D_{i} E_{i} \delta_{i}}{\sum_{i=1}^{t_{p}} D_{i} E_{i}}
$$


$D_{i}=$ Distance in kilometres of trip $i$

$E_{i}=$ The essentiality of trip $i$, where $E_{i}=1$ if the trip was optional, $E_{i}=2$ if the trips was necessary, and $E_{i}=3$ if the trip was essential

$\delta_{i}=1$ if the trip was carried out by car, and no alternatives were indicated

$\delta_{i}=0$ otherwise (i.e. non-car trip, or option of a non-car mode for trip $i$ ).

$t_{p}=$ The number of trips for person $p$

The score has a numerical value between 1 (highly adaptable) and 0 (not adaptable). A high adaptability score would mean either that most important travel is carried out without using a car or that the normal car trips are adaptable to a lower energy intensity mode in any of the three choices of alternatives. A low adaptability score would mean that all of the important activities are accessed by car with a long commute, and that very few trips have reported mode alternatives.

The data collected in Dunedin for importance of trips is shown in Figure $6(3,17)$. Seeking medical treatment, work and education are the most important trips. Social visits, entertainment, recreation and shopping are the least important trips. As with previous fuel shortages, if people reduce optional travel, then the adaptive potential is as much as $11 \%$ trip reduction.

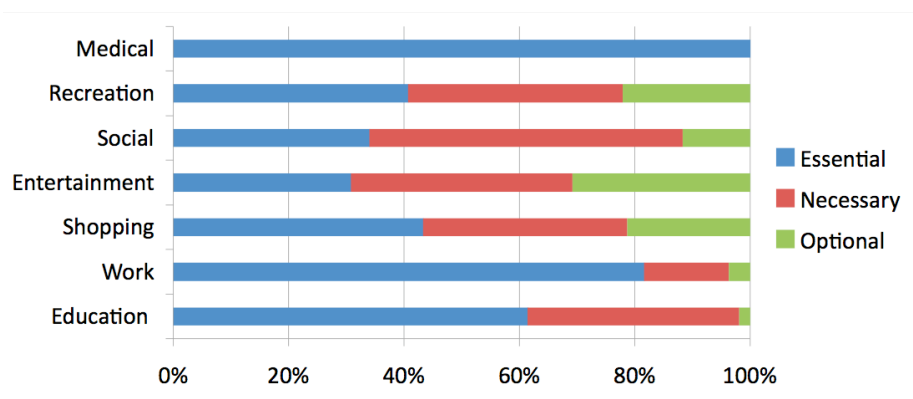

Fig. 6: Participants selected the purpose and ranked the importance of each trip. The optional trips represent $11 \%$ of all trips in Dunedin

The case study data for travel mode adaptive potential is shown in Figure 7. The student participants had a high percentage of walking trips to university as many of them lived in the dormitory areas near the university. The $40 \%$ of non-car trips by Dunedin residents accounted for $15 \%$ of kilometers. The activity system for an urban area is more resilient to a fuel shock if a larger percentage of trips are done without a vehicle. Figure 7 shows that $28 \%$ of all kilometers traveled in the week by the participants are not adaptable from private vehicle to a more fuel-efficient mode. On the other hand, Dunedin participants reported that they currently have an alternative mode for $67 \%$ of current car trips.

The high level of adaptive potential is not surprising considering the compact urban form of the city as shown in Figure 8 . The city was established in the $19^{\text {th }}$ Century when wealth from a gold boom invested the city with an iconic

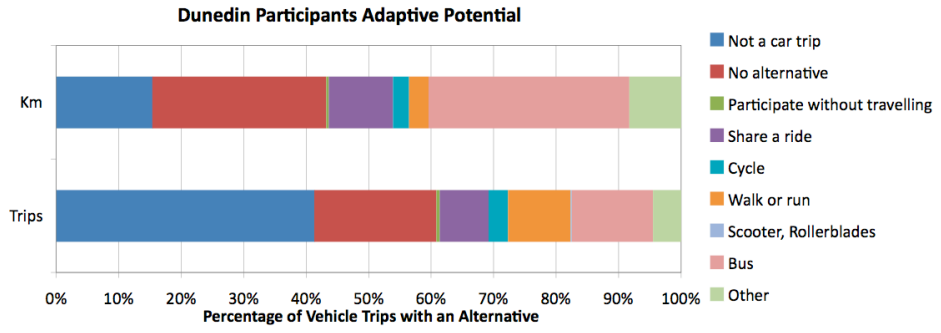

Fig. 7: Each trip reported in Dunedin is associated with a travel distance, the current mode and up to three alternative modes. The figure shows the normal car and non-car trips, plus the first choice alternatives for normal car trips.

central area connected to surrounding residential and industrial areas by trolleys and trams. The city was connected to the rest of the country by rail and to the world by the port. The hills surrounding the city were converted to lumber, dairy, wool and farming production. The majority of residents of the city live within $6 \mathrm{~km}$ of the university, central business district, industrial areas and the railhead. The port is a separate small town $16 \mathrm{~km}$ along the north of the bay, but is connected to Dunedin by a rail line. Figure 8 shows the personal adaptability of all participants plotted at their residential location. There is a pattern of high adaptability of people who live in the city, and some people living in the outlying settlements also have alternatives to the car.

\section{RESILIENCE OF URBAN FORMS}

The approach taken by the AEMSLab to bring peak oil planning into local policy and planning is to use the concepts from natural hazards engineering. Risk assessment is the first step, followed by evaluation of adaptive capacity and resilience and development of management strategies and action plans. The hypothesis is that resilience of a city to oil shocks and long term oil supply decline is primarily a function of geography of the built environment. The Minimum Energy Transport Accessibility (META) analysis method was developed to provide a resilience assessment for a urban study area which could be as small as a few square kilometers, or as large as the whole city. (18) The method uses geographic information system (GIS) data of the residential locations, activity destinations, and transportation networks to calculate the distance between origins and destinations. Demographic data for the study area is used to develop an activity model which provides the distribution and frequency of trips to different destinations and the physical ability to walk or bike a range of distances.

Figure 9 gives the result of a sample META analysis for Dunedin. The active mode accessibility for each residence in the city was calculated for the nearest supermarket or retail food store. A colored marker was plotted at the residential location of each house which indicates whether the nearest supermarket was within walking distance (green), biking distance (yellow), or outside the active access distance (red) for the general population. The results show a high resilience for 


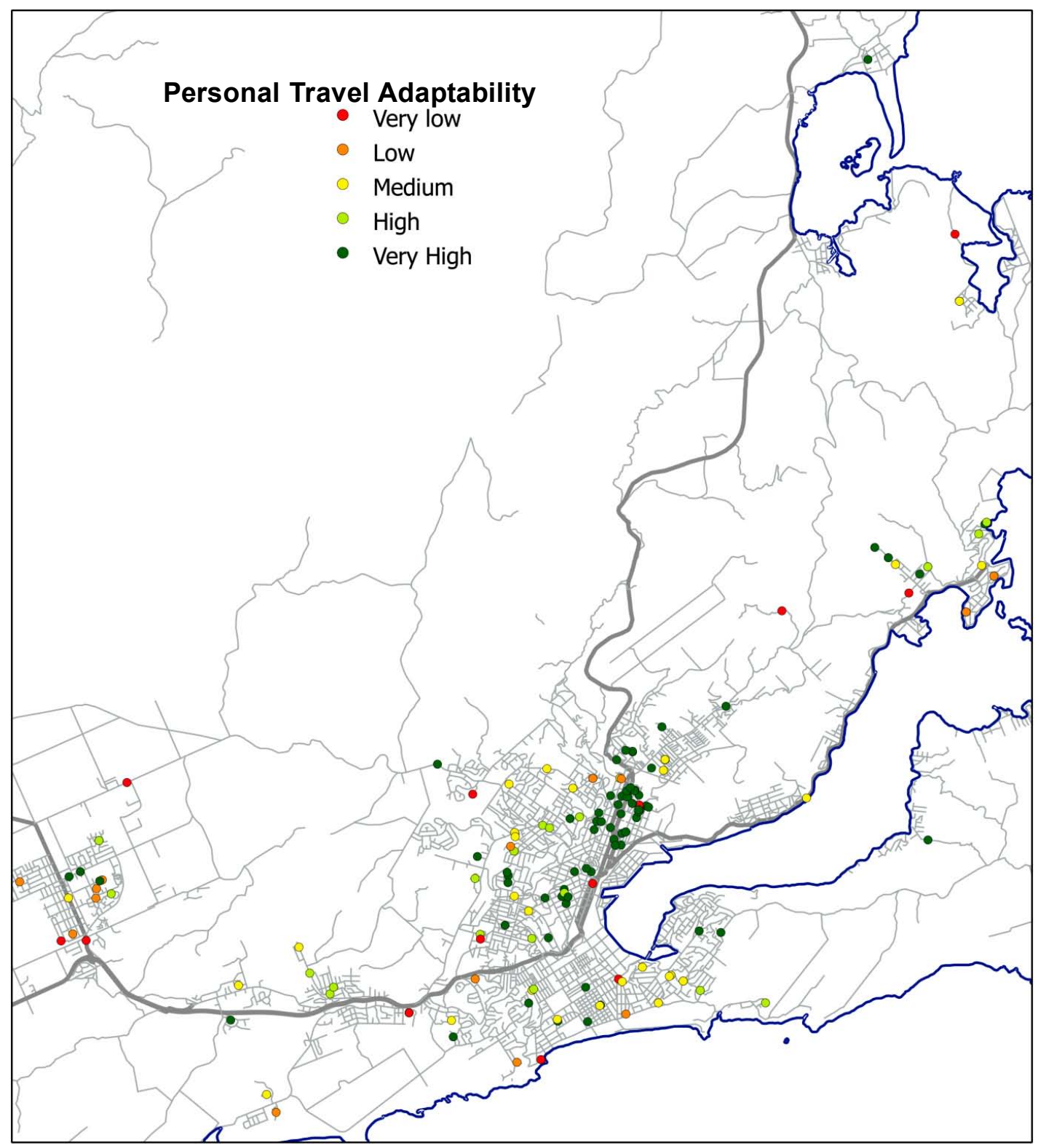

Fig. 8: The personal travel adaptability for each participant calculated from Equation 4 and plotted on the residential address.

the urban areas of the city with nearly all homes within walking or biking distance to a grocery store along existing streets and paths. There has been a trend over the past two decades of people who work or attend school in the city living in rural areas as a lifestyle choice. While the distances to the city supermarkets are not large by North American standards, these rural lifestyle households are definitely not as resilient to oil shocks or long term oil supply decline. The areas where resilience is low would be expected to experience greater pressure for change with peak oil.

\section{STRATEGIC ANALYSIS OF COMPLEX SYSTEMS}

Policy makers and advocates have discussed various possible peak oil mitigation measures. In New Zealand, while the government does not explicitly acknowledge that declining world oil supply could be a problem, the national energy strategy mentions electric vehicles, biofuels and other nonspecific "alternatives" in relation to future transportation developments (19). Although rigorous analysis of the technical feasibility, market availability, or economic viability of these alternatives is missing from the policy development, one thing is clear - the national campaign of road-building and historical patterns of urban development will continue into the future as the government ties economic growth to increasing travel demand (20).

There are advocates for "sustainable transport" in New Zealand as in other countries. These strategies usually focus on reducing urban pollution and carbon emissions and dealing 

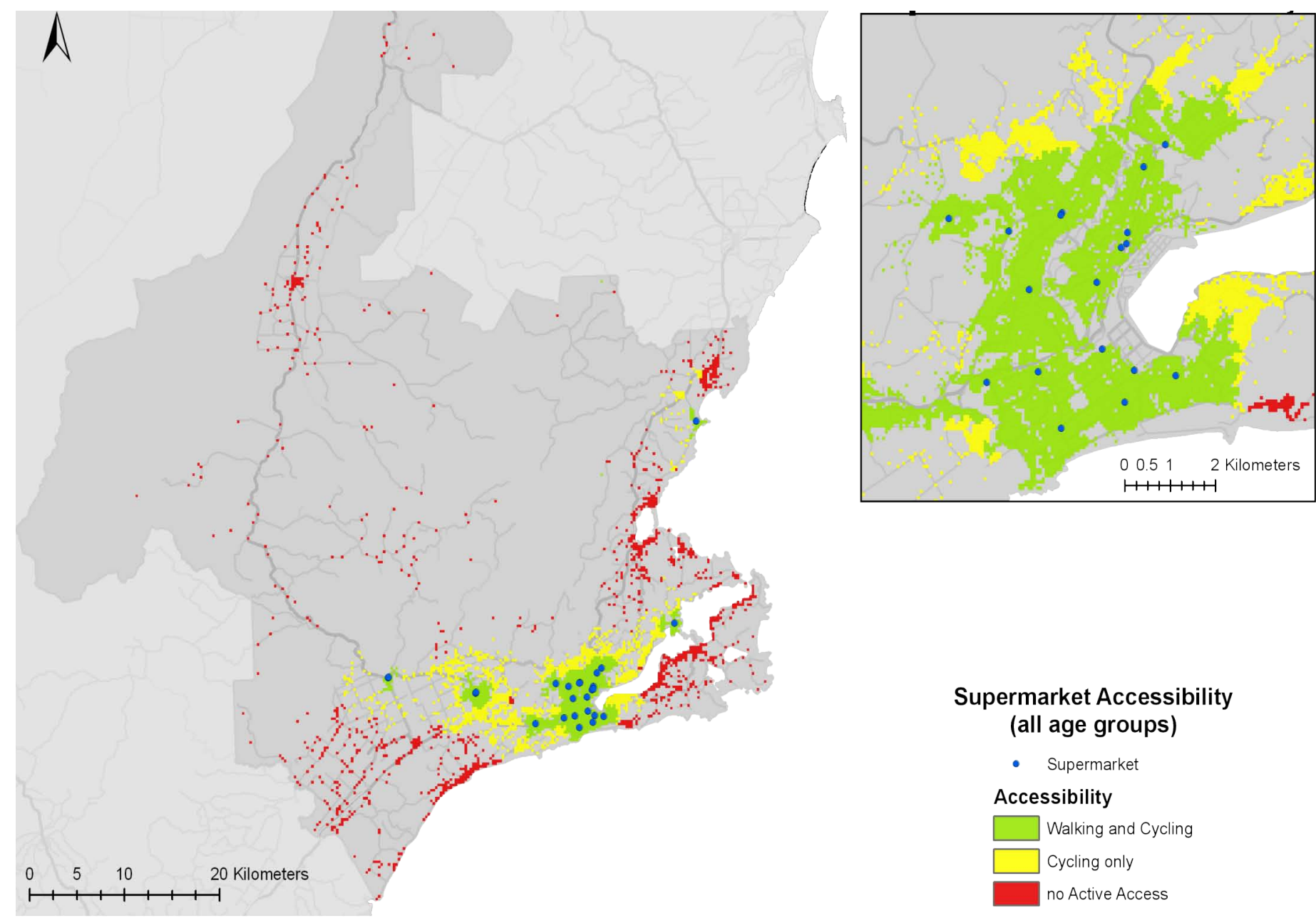

Fig. 9: The active mode accessibility for the residential population of the greater Dunedin area for access to supermarkets or grocery stores.

with congestion through increased public transportation and active modes (21). The government is also concerned about imported oil, but the analysis of the risks posed by oil supply issues is only found in one statement in the national strategy:

"Both security of oil supply and price are key challenges for the transport sector in New Zealand, which is highly dependent on fossil fuels. If oil shortages or high costs occur before alternatives can be found, this would have a negative impact on the New Zealand economy. It would also have major implications for the lives of New Zealanders, particularly those on low incomes." (21)

An important development to come out of the AEMSLab research is the method called Strategic Analysis of Complex Systems (SACS) (22). The SACS method was developed as a way to integrate policy development, public communication and engineering analysis. The method involves firstly organizing development alternatives according to categories technology, resources, and infrastructure or built environment. A range of scenarios is then set out that define the level of service at a future development point. The candidate development alternatives are then laid out in a matrix that defines the Possibility Space. Engineering analysis is performed on each of the possibilities in the matrix to determine technical and resource feasibility to meet the level of service targets. Possibilities that are not feasible are eliminated from the Possibility Space. Risk analysis and cost analysis are then performed on each of the remaining possibilities. Risks can include supply security, environmental impact, social pressures, economic uncertainty and considerations of future needs. The lower risk possibilities then form the Opportunity Space, which become the focus for future development and policy action (23).

A case study using the method was carried out for the Peak Oil Vulnerability assessment for the city of Dunedin (3). Figure 10 shows the results of the SACS investigation for private vehicle transportation in the city and settlements. As discussed earlier, different people within the community and the council held different ideas about the need for peak oil adaptation policy and about what the "solutions" might be. The urban form development adaptations shown as columns in the possibility 
space matrix reflect the most common visions of future development found in discussions with residents, council workers and business people. The rows represent adaptive trends in alternative fuels, vehicles, public transportation and behavior changes. In presentations, discussions and follow-up email conversations with people from Dunedin, there have not been any other development possibilities that people felt were not included, and all felt that their particular "solution" idea was represented in the possibility space. A target date of 2050 was chosen for the target and a neutral 50\% probability for the world oil supply scenario gave roughly a 50\% transport fuel supply reduction for the strategic analysis to address. Even though the behavior adaptation is named "low carbon lifestyle" carbon emissions were not a feature of this analysis. The behavior adaptations encompass decision-making about where to live, shopping locally, and using public transport and active modes whenever possible in order to achieve $50 \%$ reduction in fuel demand from current levels. META Analysis of the urban form and TACA surveys of the residents indicated that this is an achievable goal even in the current urban form.

Figure 10 shows that meeting the 2050 fuel supply reduction target was not possible by substituting biofuels or electric cars. Some of the council policy makers struggled to understand the technical analysis that showed New Zealand could not produce sufficient biofuels to provide $50 \%$ of current fuel demand, nor could electric vehicles be available in the numbers or at the costs affordable for Dunedin within 40 years (24). Some of the most ardent peak oil advocates in Dunedin were not satisfied that opportunities were identified for future development that preserved activity systems as they consider economic collapse will cause food supply and civic disaster. They also felt that $50 \%$ supply reduction target was too optimistic.

\section{PRIMARY PRODUCTION, FREIGHT AND GOODS MOVEMENTS}

Private transport consumes just more than half of the liquid fuel in New Zealand and personal access to transport activity systems is a major vulnerability as in many other countries. However, the other sectors including primary production, construction, services, freight and goods movement are critical to the economy and the wellbeing of the population. The higher freight energy efficiency per ton-km of freight and costal shipping is well known. However, the economics of "just in time" shipping, where warehousing is eliminated by on-demand truck transport, has greatly favored increased truck and air freight over more economical, but slower rail and shipping. Technical energy efficiency of trucks has been improving and driver training can reduce energy use (25). Recently, $\mathrm{CO}_{2}$ emissions and "food miles" have been areas of research $(26$, 27). However, the area of fuel supply risk to freight movements is largely unexplored in the transportation research literature. Adaptation of production and freight systems to reduced fuel use has not been investigated, and resilience to fuel price rise has not been widely studied (27).
The AEMSLab research approach for freight and primary production takes the same perspective as for personal transport. First we aim to develop risk assessment methods, then ways to evaluate adaptive capacity and resilience, and finally engineering and modeling tools to manage risk and reduce energy demand. The emphasis on setting up specific study areas within local council authority is being used for freight as well. The first $\mathrm{PhD}$ thesis on assessing peak oil risk to freight movement is nearing completion, and another on local energyconstrained development of production, processing and market systems is in progress.

Geography is a deterministic factor at either end of the freight system as primary production is located according to resource availability and the consumers are located in urban areas. Most older cities have grown up in a particular location because of access to freight transport. Pittsburgh, Pennsylvania is an example of a city that grew at the juncture of three navigable rivers and rail lines that transported coal and iron ore from mines to the factories in the city, and then took finished steel to markets. Pittsburgh is also an example of how urban form is shaped by the local geography, industrial activities, markets, the housing of workers, and importantly, the transport networks that connected the sprawling activities. The model industrial suburban town of Vandergrift is also an example of a planned urban development with environmental and social welfare considerations in the urban design, and it is connected to Pittsburgh by rail transport.

Commercial transport behavior is similar to personal transport behavior in that decisions about locating warehouses, using various transport modes, routes and logistics etc. are based on a wide range of factors, other than fuel use. Previous experience or "habit" is a particularly important factor. While fuel costs are a concern for business and freight companies, energy use, and in particular the possibility of fuel supply constraint, has not been a real consideration in commercial transport behavior. A major challenge for researchers is the critical lack of available data. Current AEMSLab research is working on ways to acquire commercial transport behavior data from existing sources and simple survey methods. The research team is working with retailers, freight companies and local councils to develop useful local supply chain risk assessment and planning analysis tools.

\section{SUMMARY AND FUTURE WORK}

Peak oil has implications for all aspects of modern societies. However, transportation is the obvious critical area of risk exposure. Experts have understood the issue of peak oil for many years, but more detailed analysis of the problem has not produced policy action or technical solutions. When a new problem or opportunity arises, one of the first policy actions is usually funding of research. The issue of peak oil has been largely ignored because of the perceptions that alternatives will come into the market in response to price signals and the market will take care of the issue. 


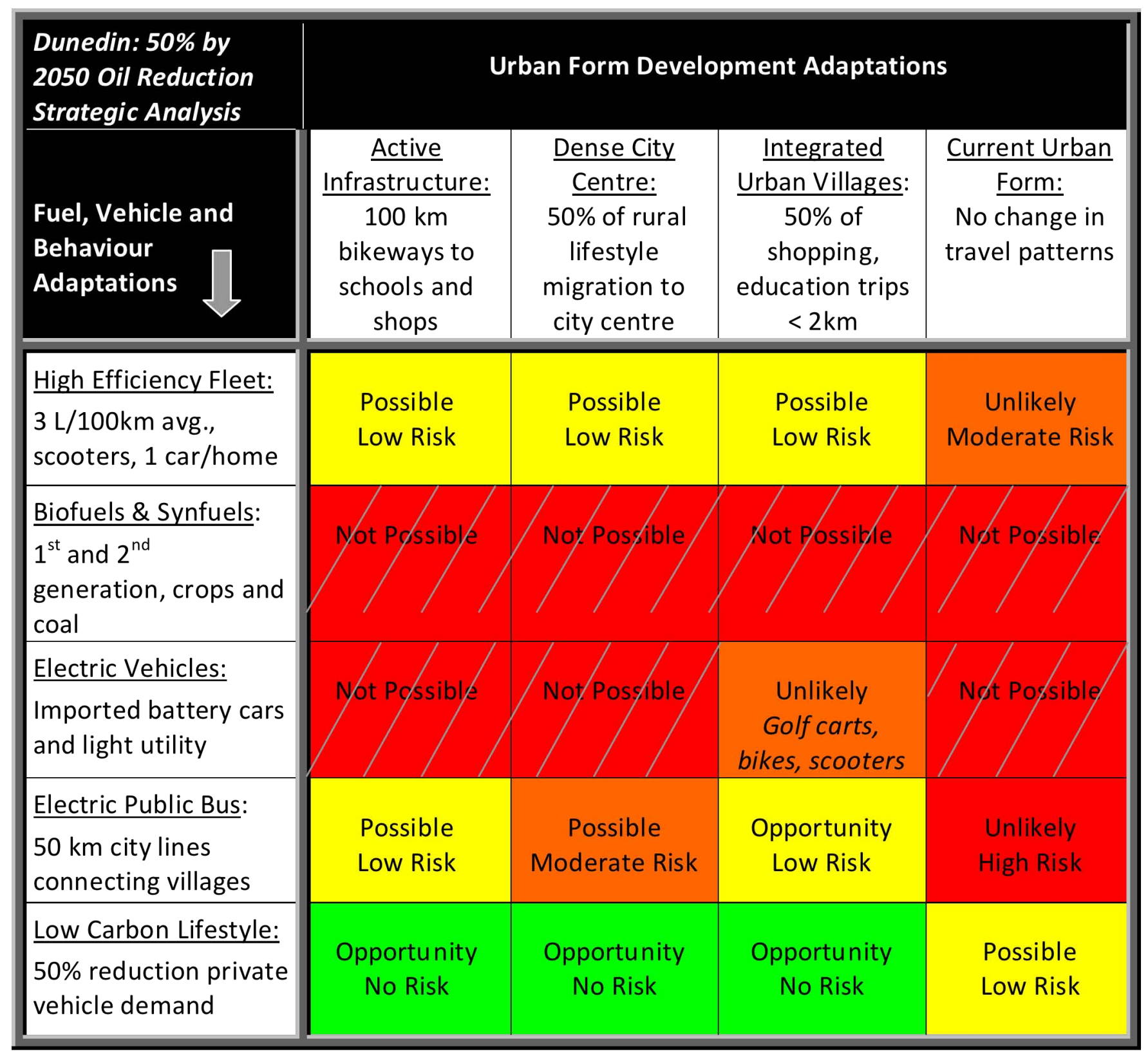

Fig. 10: The Opportunity Space for Dunedin, New Zealand is shown as un-hatched areas of the Possibility Space matrix formed by laying out urban form and infrastructure development plans in the columns with technology, resource and behavior options in the rows.

It is time for researchers to move beyond warning of fuel price increase and the possibility of peak oil. Additionally, current research literature often suggests broad or generic strategies without any analysis or methods that can be applied at the local level. It is time for technology experts and researchers to give accurate and realistic assessments of the potential of alternative technologies and fuels. It is past time that transportation engineering and urban planning researchers make fossil fuel energy reduction a major focus in their discipline. Currently the main problem with getting policy action is the lack of communication and processes that would be followed to develop action plans. Policy and business action will be possible when there are a range of development alternatives to discuss.

This paper has provided an overview of the work of one interdisciplinary research group directed by Dr. Krumdieck at the University of Canterbury in the rather remote location of Christchurch, New Zealand. Over the past decade, the AEMSLab research group has focused on developing Transition Engineering methods for dealing with peak oil and fossil fuel demand reduction. The AEMSLab approach has 
been to borrow core ideas from the Natural Hazards Engineering field to facilitate communication and action planning. The research has progressed well through the concepts of identification of issues, risk assessment, evaluation of adaptive potential and resilience. The data collection and modeling programs developed by the group have focused on capability for Transition Engineering at the local scale.

The first project was to develop a method to assess risks to personal transport activity systems with long term planning in mind. The RECATS program has been effective in moving the discussion of peak oil out of the realm of a frightening prospect and into the realm of transportation and urban planning. The second project was to develop a way to assess transport adaptive capacity for a given local urban form. The TACA survey has been successfully deployed in several different cities and the results have added new insights into the potential for mode change. The third project was to develop a method to assess the geography of an urban area for minimum energy and active mode accessibility for the given population. The META program has been taken up by a transportation consulting firm and has the potential to be used in the long-term planning for re-building the earthquake devastated city of Christchurch as a sustainable city. The fourth project developed the strategic analysis method for complex systems as a way to inject engineering analysis and a communication and decision making aide into the processes of local long-term planning. The SACS method has been used in several instances with local councils to look at different issues and has helped to transition policy discussion from individual advocacy to organizational action. Future work in the AEMSLab group is focusing on developing Transition Engineering methods for primary production, processing, services, freight and urban goods movement.

\section{ACKNOWLEDGEMENTS}

The research from the AEMSLab is the work of many students and academics from a diverse set of backgrounds. Key academic researchers are Andre Dantas, Transportation Engineering, Shannon Page, Energy Systems Engineering, Richard Green, Computer Science, Elijah van Houten, Computational Methods, Femke Reitsma, Geography, and Rua Murray, Mathematics. Masters student Michael Saunders first investigated risk, and over 15 undergraduate intern engineering students have helped collect data and build models. PhD students have put in the hard work to develop the Transition Engineering tools; Tony Burton, Michael Dale, Montira Watcharasukarn, Aline Lang, Stacy Rendall, Robert Snook, and Janice Asuncion. The research work presented in this paper was funded from a range of grants, scholarships and personal resources including, Land Transport New Zealand, Brian Mason Scientific Trust, New Zealand Transport Authority, National Energy Research Institute, the Foundation for Research Science and Technology, and Departments of Civil and Mechanical Engineering, University of Canterbury.

\section{REFERENCES}

1 Sorrell, S., Speirs, J., Bentley, R., Brandt, A., Miller, R., Global Oil Depletion, Report produced by the Technology and Policy Assessment function of the UK Energy Research Centre, 2009.

2 Hirsch, R.L., Mitigation of maximum world oil production: shortage scenarios, Energy Policy, 36, 881-889, 2008.

3 Krumdieck, S., Peak Oil Vulnerability Report, Report produced by EAST Research Consultants, 2010.

4 Bardi, U., Peak Oil: the four stages of a new idea, Energy, 34, 323326, 2009.

5 Dantas, A., Krumdieck S., Page, S., Energy Risk to Activity Systems as a Function of Urban Form, Land Transport New Zealand Research Report, 311 pp. 1-73, 2007.

6 Krumdieck, S., Page, S., Dantas, A., Urban form and long term fuel supply decline: A method to investigate the peak oil risks to essential activities, Transportation Research Part A, 44, 306-322, 2010.

7 Campbell, C. J. Industry urged to watch for regular oil production peaks, depletion signals, Oil \& Gas Journal, 101 (27) 38-45, 2003.

8 Krumdieck, S., presentation video available at: $<$ http://sustainablecities.org.nz/2009/10/making-the-right-turn$\% \mathrm{E} 2 \% 80 \% 93$-susan-krumdieck/>

9 Dantas, A., S. Krumdieck, S. Page, Risk of energy constrained Activity-transport systems (RECATS), Journal of Eastern Asia Society for Transportation Studies, 7, 1154-1168, 2007.

10 Watcharasukarn, M., Travel Activity Constraint Adaptation Simulation (TACA Sim), PhD Thesis, University of Canterbury, Examined 22 November 2010.

11 Available at http://www.tacasim.aemslab.org.nz/

12 Oppenheim, N., Urban Travel Demand Modeling From Individual Choices to General Equilibrium, John Wiley \& Sons, Inc., New York, pp.20-62, 1995.

13 Peskin, R.L., Schofer, J.L., Stopher, P.R., The Immediate Impact of Gasoline Shortages on Urban Travel Behavior, Federal Highway Administration, Final Report, April 1975.

14 Chatterjee, K., Lyons, G., Travel behavior of car users during the UK fuel crisis and insights into car dependence, In: G. Lyons and $\mathrm{K}$. Chatterjee, Editors, Transport lessons from the fuel tax protests of 2000, Ashgate, Aldershot, UK, pp. 123-159, 2002.

15 StatisticsNZ (2009) Subnational population estimates at 30 June 2009: local government areas, Statistics New Zealand.

16 www.otago.ac.nz/humanresources accessed 14 March 2011

17 Krumdieck, S. Page, S., Watcharasukarn, M., Travel Adaptive Capacity Assessment, New Zealand Transport Authority, Research Report xxx, 2011. (in press)

18 Rendall, S., S. Page, F. Reitsma, E. van Houten, S. Krumdieck, Quantifying transport resilience: active mode accessibility, Journal of the Transportation Research Board, 2011. (in press)

19 New Zealand's Energy Outlook 2010, Ministry for Economic Development, 2010.

20 Government Policy Statement on Land Transport Funding, Ministry of Transport, November 2010.

21 New Zealand Transport Strategy 2008, Ministry of Transport, 2008.

22 Hamm, A., Methodology and Modelling Approach for Strategic Sustainability Analysis of Complex Energy-Environment Systems, PhD Thesis, University of Canterbury, Examined August 2007.

23 Krumdieck, S., A. Hamm, Strategic analysis methodology for energy systems with remote island case study, Energy Policy, Vol 37(9), 3301-3313, 2009. 
24 Delucchi, M.A., Lipman, T.E., An analysis of the retail and lifecycle cost of battery-powered electric vehicles, Transportation Research Part D, 6, 371-404, 2001.

25 Kamakaté, F., L. Schipper, Trends in truck freight energy use and carbon emissions in selected OECD countries from 1973 to 2005, Energy Policy, Vol37, (10), 3743-3751, 2009.

26 McKinnon, A.C., Piecyk, M.I., Measurement of CO2 emissions from road freight transport: A review of UK experience, Energy Policy, Vol 37 (10), 3733-3742, 2009.

27 Pretty, J.N., A.S. Ball, T. Lang, J.I.L. Morison, Farm costs and food miles: An assessment of the full cost of the UK weekly food basket, Food Policy, Vol 30 (1), 1-19, 2005.

28 North, P., Eco-localisation as a progressive response to peak oil and climate change - A sympathetic critique, Geoforum, Vol 41 (4), 585-594, 2010. 